\title{
PERANCANGAN COMPANY PROFILE MENGGUNAKAN ADOBE FLASH UNTUK SMARTPHONE PADA BMT AMANAH RAY
}

\author{
Ade Rezeki Siregar, Dian Noviandri, Edi Winata \\ Alumni Sekolah Tinggi Ilmu Manajemen Sukma \\ Program studi Manajemen, Sekolah Tinggi Ilmu Manajemen \\ Noviandrid161@gmail.com, ediwinatarivai11960@gmail.com
}

\begin{abstract}
The purpose of this study is to design a company profile application system that can be accessed via android smartphone on BMT Amanah Ray. The current application system on BMT Amanah Ray only has a web based profile company. The application is designed using Adobe. Adobe Flash is a software that serves to edit animation and run programs that are assisted by a smartphone as a device to run the program while. The research results have been successfully implemented so that it is expected to help the community to know information about BMT Amanah Ray more easily.

Keywords : System, Company Profile, Adobe Flash, Smartphone
\end{abstract}

\section{PENDAHULUAN}

Pada saat sekarang ini penggunaan company profile dalam bentuk hardcopy sudah tidak layak untuk dijadikan sebuah media informasi pada sebuah perusahaan maupun sebuah instansi. Perkembangan teknologi dan komputer saat ini sangatlah baik untuk pengembangan sebuah media informasi yaitu company profile. Dengan penggunaan Adobe Flash company profile dapat dijalankan di media komputer maupun smartphone. Penggunaan media komunikasi yaitu smartphone yang saat ini sangat digemari sangatlah cocok untuk dijadikan sebagai alat penyampaian informasi yang sangat komplit. Pembuatan company profile menggunakan adobe flash ini bisa memberikan informasi dengan lebih mudah, penggabungan multimedia dengan smartphone akan menciptakan sebuah aplikasi yang sangat bagus sebagai media informasi. Pemilihan animasi dan hiasan hiasan yang tepat dalam pembuatan company profile akan menjadi daya tarik tersendiri bagi para calon nasabah.

Penelitian Menurut Rina dan Nuryna (2012) dengan judul Pembuatan Company Profil Berbasis Multimedia Flash PD BPR Bank Daerah Karanganyar, dari hasil penelitian menyatakan bahwa company profile berbasis multimedia flash diharapkan dapat digunakan sebagai sarana promosi dan informasi. Penelitian yang dilakukan oleh Irfan (2013) dengan judul Pembuatan Video Company Profile Pada Belukar Merch di Kelurahan Jayengan Kecamatan Serengan Kota Surakarta menyatakan bahwa pembuatan video company profile berbasis multimedia pada Belukar Merch akan mendukung kegiatan promosi dan penyebaran informasi sehingga menjadi lebih efektif dan efisien dari segi waktu, biaya, serta tenaga. Penelitian menurut Firdaus dkk (2012) dengan judul Perancangan Aplikasi Multimedia Interaktif Company Profile Generic menyatakan bahwa multimedia interaktif yang dibuat menggunakan metodologi pengembangan multimedia versi Sutopo-Luther merupakan aplikasi generic dimana pengguna bisa merubah konten sesuai dengan kebutuhan baik merubah teks, menu, logo, background, gambar mapupun video maka aplikasi ini bisa di gunakan ulang oleh perusahaanperusahaan lainnya. 


\section{Perumusan Masalah}

Perumusan masalah dalam penelitian ini adalah bagaimana merancang sistem company profile menggunakan adobe flash untuk smartphone pada BMT Amanah Ray?

\section{Batasan Masalah}

Untuk memperjelas arah dalam pembuatan aplikasi ini maka batasan masalah yang di ambil penulis untuk proposal penelitian ini sebagai berikut :

1. Program menggunakan software Adobe Flash.

2. Objek penelitian yang dibahas mengenai produk simpanan dan pembiayaan.

3. Aplikasi hanya dapat dibuka melalui smartphone android.

\section{Tujuan Penelitian}

Adapun tujuan dari penelitian ini adalah untuk merancang sistem aplikasi company profile pada BMT Amanah Ray yang dapat diakses melalui smartphone android.

\section{METODE PENELITIAN}

\section{Tempat dan Waktu Penelitian}

Penelitian dilakukan di KSPPS BMT Amanah Ray Medan cabang Marelan, yang berlokasi Jl. Marelan raya pasar 3 No. 144A. Dimulai dari bulan Februari sampai dengan Juni 2017.

\section{Jenis dan Sumber Data}

\section{Jenis Data}

1. Data Primer adalah data asli yang dikumpulkan sendiri oleh peneliti untuk menjawab masalah penelitiannya secara khusus.

2. Data Sekunder adalah data yang bersumber dari catatan yang ada pada perusahaan dan dari sumber lainnya yaitu mengadakan studi kepustakaan dengan mempelajari bukubuku yang ada hubungannya dengan objek penelitian.

\section{Sumber Data}

1. Data internal adalah data yang didapat dari tempat penelitian seperti hasil observasi dan dokumen perusahaan.

2. Data eksternal adalah data yang didapat dari luar tempat penelitian berupa buku penunjang sebagai bahan bacaan dan landasan teori yang relevan dengan permasalahan yang diteliti.

\section{Metode Pengumpulan Data}

1. Studi Dokumentasi: pengumpulan data yang dilakukan dengan mencari informasi berdasarkan dokumen-dokumen perusahaan yang berkaitan dengan penelitian.

2. Observasi: pengamatan data melalui pengamatan secara langsung di BMT Amanah Ray Medan Cabang Marelan.

\section{Metode Analisis Data}

Adapun metode analisis data yang penulis gunakan adalah deskriptif kualitatif.

\section{Perangkat Keras}

Perangkat keras yang digunakan sebagai sarana pendukung dalam penelitian perancangan sistem company profile ini adalah perangkat yang meliputi :
a. Notebook : AspireOne D255
b. Memori : 1 GB DDR3 Memory
c. $C P U$
d. Storage : $320 \mathrm{~GB}$ HDD 


\section{Perangkat Lunak}

Perangkat lunak yang digunakan dalam penelitian ini menggunakan sistem operasi Microsoft Windows 7 dengan aplikasi program yaitu Adobe Flash dan Android.

\section{Konsep Desain}

Konsep desain yang digunakan dalam program ini adalah mengambil tema warna dari perusahaan BMT AMANAH RAY sendiri yaitu, Biru, Gold, hijau dan Putih.

Berikut rincian konsep desain:

a. Dalam menu tampilan awal (beranda) terdapat empat button yaitu, galeri, profil, produk dan kontak.

b. Menu galeri terdapat foto-foto direktur beserta karyawan BMT Amanah Ray.

c. Menu profil terdapat empat button yang masing masing berisi tentang sejarah perusahaan, program, visi dan misi serta button menu beranda.

d. Menu produk berisi tentang simpanan dan pinjaman beserta penjelasannya.

e. Menu kontak berisi tentang alamat dan kontak.

f. Font dalam program ini penulis menggunakan font Algerian, Eccentric Std, Monotype Corsiva karena font tersebut akan terlihat elegant ketika dilihat oleh viewer.

g. Background dalam program ini penulis mengambil tema hexagon agar terlihat lebih menarik bagi para viewer.

\section{HASIL PENELITIAN DAN PEMBAHASAN}

\section{Hasil Penelitian}

Hasil penelitian ini diperoleh setelah penulis melakukan penelitian dan menganalisa hingga merancang company profile untuk smartphone pada BMT Amanah Ray. Nasabah dapat mengetahui informasi terbaru mengenai BMT Amanah Ray yang dapat diakses melalui smartphone android.

\section{Pembahasan}

Sub bab ini akan membahas mengenai sistem aplikasi company profile untuk smartphone yang telah dibuat. Sesuai dengan perumusan masalah yaitu bagaimana merancang sistem company profile menggunakan adobe flash untuk smartphone pada BMT Amanah Ray. Berikut uraian pembahasan setelah penulis melakukan perancangan sistem, maka hasil penelitian yang telah diselesaikan adalah sebagai berikut:

1. Halaman awal aplikasi

Halaman ini menampilkan halaman utama aplikasi ketika masuk ke dalam sistem company profile BMT Amanah Ray.

\section{Tampilan Halaman Beranda}

Pada halaman beranda ini akan ditampilkan pilihan-pilihan menu yang pada setiap menu menampilkan informasi-informasi tentang BMT Amanah Ray yang dapat membantu nasabah.

\section{Tampilan Halaman Profil}

Halaman ini menampilkan uraian singkat mengenai BMT Amanah Ray dan pada menu ini terdapat beberapa pilihan informasi BMT Amanah Ray. Pilihan tersebut diantaranya yaitu:

a. Sejarah: berisi informasi mengenai sejarah BMT Amanah Ray dari awal berdiri hingga serta perkembangannya hingga sekarang.

b. Visi dan Misi: berisi informasi mengenai visi dan misi BMT Amanah Ray

c. Program: berisi informasi mengenai program apa saja yang dilakukan BMT Amanah Ray. 
4. Tampilan Halaman Produk

Pada halaman ini akan ditampilkan beberapa layanan yang disediakan BMT Amanah Ray. Dalam halaman ini BMT Amanah Ray menjelaskan mengenai enam bentuk simpanan yang disediakan diantaranya:
a. Tabungan Biasa
b. Tabungan Berjangka
c. Tabungan Pendidikan
d. Tabungan Idul Fitri
e. Tabungan Haji
f. Tabungan Qurban

Dan pada halaman ini juga ditampilkan informasi mengenai layanan pembiayaan yang diberikan BMT Amanah Ray diantaranya :
a. Mudharabah
b. Musyarakah
c. Murabahah
d. Bai'Bitsaman'Ajil

\section{Tampilan Halaman Gallery}

Halaman gallery akan menampilkan gambar-gambar atau foto-foto dari cabangcabang BMT Amanah Ray dalam berbagai acara.

6. Tampilan Halaman Kontak

Halaman ini akan menampilkan informasi mengenai alamat dan kontak yang bisa dihubungi dimana terdapat delapan buah alamat yang ditampilkan .

\section{KESIMPULAN}

Berdasarkan hasil penelitian yang telah diuraikan di bab sebelumnya, terdapat beberapa kesimpulan sebagai berikut:

1. Dengan adanya company profile yang dapat diakses melaui smartphone ini dapat membantu masyarakat baik itu nasabah maupun calon nasabah untuk mengetahui tentang profil perusahaan BMT Amanah Ray.

2. Dapat memudahkan account officer dalam mencari nasabah baru. 


\section{REFERENCES}

Batubara, A., \& Hidayat, R. (2016). Pengaruh Penetapan Harga dan Promosi terhadap Tingkat Penjualan Tiket pada PSA Mihin Lanka Airlines. Jurnal Ilman, 4(1), 3346.

Cece. (2003). Analisis Hubungan Perencanaan Strategi Aliansi PDAM Tirtanadi-PT. Telekominikasi Divre I Terhadap Peningkatan Kualitas Pelayanan Pelanggan PDAM Tirtanadi... Universitas Sumatera Utara.

Dinamika, S. G. (2018). Gemstone Fever Hits Jakarta: A Lexical Meaning Analysis.

Dinamika, S. G., \& Sari, W. V. (2015). Applied Error Analysis of Comparative Degree Sentence Construction of Students in STIM Sukma Medan. Asian EFL Journal, 5, 112-119.

Dinamika, Soraya Grabiella (2014) THE EFFECT OF USING COLLABORATIVE STRATEGIC READING ON STUDENTS' ACHIEVEMENT IN READING NARRATIVE TEXT. Undergraduate thesis, UNIMED

Fajarianto, O., Triono, \& Cahyandi, F. (2015). Perancangan Pembuatan Multimedia Pembelajaran " Hukum Newton Tentang Gaya Dan Gerak” Berbasis Adobe Flash, $5(1), 1-5$.

Fathimah, V. (2017). Pengaruh Perkembangan Jumlah Tabungan, Deposito dan Bagi Hasil terhadap Jumlah Pembiayaan yang Diberikan oleh Perbankan Syariah di Sumatera Utara. Jurnal Ilman, 5(1), 41-52.

Firdaus, S., Damiri, Johar, D., \& Tresnawati, D. (2012). Perancangan Aplikasi Multimedia Interaktif Company Profile Generic, 1-10. Retrieved from jurnal@sttgarut.ac.id

Hartono, B. (2013). Sistem Informasi Manajemen Berbasis Komputer. Jakarta.

Helmawati. (2015). Sistem Informasi Manajemen Pendidikan Agama Islam. (N. N. Mulia, Ed.) (1st ed.). Bandung: PT. Remaja Rosdakarya.

Hidayat, R. (2009). Penerapan Sistem Informasi Manajemen sebagai Alat Pelaksanaan Sistem Administrasi Akademik. JURIDIKTI: Jurnal Ilmiah Pendidikan Tinggi, 2(2), 56-59.

Hidayat, R. (2010). Analisis Tingkat Penggunaan Internet Dikalangan Mahasiswa dan Hubungannya dalam Peningkatan Nilai Akademik (Studi Kasus pada Mahasiswa di Kota Medan). Jurnal Mediasi, 2(2), 55-63.

Irfan, M. (2013). Pembuatan Video Company Profil Pada Belukar Merch Di Kelurahan Jayengan Kecamatan Serengan Kota Surakarta Mohammad Irfan Keywords: Video Company Profile, Belukar Merch Kata Kunci: Video Company Profil , Belukar Merch, 2(1), 50-54.

Juhara, Z. P. (2016). Panduan Lengkap Pemrograman Android. (P. S. Wibowo, Ed.). CV. ANDI OFFSIT.

Maulana, I. (2014). Pemrograman Game Dengan Actionscript 3.0 Pada Adobe Flash Cs6. (A. Sahala, Ed.). C.V ANDI OFFSET.

Nasution, W. A. (2009). Pengaruh kepuasan kerja karyawan terhadap intensi turnover pada call center Telkomsel di Medan. Jurnal Mandiri, 4(1), 1-11.

Nasutiona, L. K., Fahrurb, M., Christine, Imaduddind, \& Wardayani. (2017). The Calculation of Cost of Goods Sold "Gayo Arabica Coffee from Takengon" with Variable Costing Method. Journal Online Jaringan COT POLIPD (JOJAPS), 10, 82-87. 
Ningratri, Y. A. (2017). Analisis Pengaruh Strategi Bauran Pemasaran Jasa (3P) terhadap Keputusan Mahasiswa Memilih STIM Sukma Medan. Riset \& Ejurnal Manajemen Informatika, 3(1), 50-56.

Nurlinda, \& Wardayani. (2014). Pengaruh Partisipasi Penyusunan Anggaran Dan Penggunaan Instrumen Manajemen Terhadap Kinerja Pengelolaan Dana Bantuan Global Fund Komponen Aids Pada Kementerian Kesehatan Ri. Jurnal Ilman, 1(1), 23-35.

Prabawati, A. (Ed.). (2015). Membuat Company Profile dengan Adobe Flash CS6. Semarang: C.V ANDI OFFSET.

Prana, R. R. (2016). Analisis Faktor-faktor yang Mempengaruhi Pendapatan Asli Daerah (PAD) Kota Tebing Tinggi. Jurnal Ilman, 4(1), 74-86.

Pratama, putu agus eka. (2014). Sistem Informasi dan Implementasinya (1st ed.). bandung: informatika bandung.

Purnomo, E. K. O. (2013). Perancangan company profile sekolah alam minangkabau dalam bentuk media audio visual.

Raidani, Pertiwi, L. S., Wulandari, D. Y., \& Zuhri. (2016). Tobit and Interval Censored Regression Model. Global Journal of Pure and Applied Mathematics, 12(1), 981994.

Rina, Arica, R., \& Nuryna, Fiska, A. (2012). Pembuatan Company Profil Berbasis Multimedia Flash PD BPR Bank Daerah Karanganyar. Journal Speed - Sentra Penelitian Engineering Dan Edukasi, 4(2), 8-13. Retrieved from ijns.org.

Safaat, N. (2015). Android Pemrograman Aplikasi Mobile Smartphone dan Tablet PC Berbasis Android. Bandung: informatika bandung.

Sinuhaji, E. (2013). PENGARUH BUDAYA ORGANISASI TERHADAP KEPUASAN KERJA KARYAWAN PADA JASA PERHOTELAN (Studi Kasus di Garuda Plaza Hotel Medan). Bisnis Administrasi, 2(1), 2537.

Sukendro, H. A. (2012). Pengaruh Citra Merek dan Kualitas Pelayanan terhadap Kepuasan Jama'ah pada Kelompok Bimbingan Ibadah Haji (KBIH) Indosat Medan. Universitas Terbuka.

Sunyoto, D. (2013). Sistem Informasi Manajemen Perspektif Organisasi. (T. Admojo, Ed.) (1st ed.). jakarta: CAPS (Center of Academic Publishing Service).

Sutarbi, T. (2012). Analisis Sistem Informasi. (C. Putri, Ed.). Yogyakarta: CV ANDI OFFST.

Widjanarko, B. (2015). PENGARUH PEMERIAN KOMPENSASI DAN KOMUNIKASI TERHADAP SEMANGAT KERJA KARYAWAN PADA BUMI KARYA TAMA INSURANCE CABANG MEDAN. Jurnal Research Sains, 1(2), $130-152$.

Winata, E. (2015). Pengaruh Pemberian Kompensasi dan Penilaian Prestasi Kerja terhadap Produktivitas kerja Karyawan pada PT. Askrindo cabang Medan. Jurnal Dunia Ilmu, 1(2).

Winata, E. (2016). Pengaruh Kepuasan Kerja dan Kompensasi terhadap Kinerja Karyawan pada Hotel Inna Dharma Deli Medan. Jurnal Ilman, 4(1), 1-17.

Zuhri, \& Pertiwi, L. S. (2016). Airline revenue management under number of no-shows uncertainty. Global Journal of Pure and Applied Mathematics, 12(1), 1003-1012.

Zuhri. (2015). Model Input Output dan Aplikasinya pada Enam Sektor. Jurnal Ilman, 3(1), 16-21. 